\title{
EXFOLIATION OF NANOGRAPHENE FROM WASTE BATTERIES AND ITS APPLICATION IN METHYLENE BLUE DYE REMOVAL
}

\author{
K.BOGESHWARAN ${ }^{a}$, K.SATHISH KUMAR $^{b}$, B.KARUNANITHI $^{c}$, M.SRIVIDHYA $^{a}$ AND G.GOWRI $^{a}$ \\ ${ }^{a}$ Agni College of Technology, Department of Chemical Engineering, Thalambur, Tamil Nadu 600130, India. \\ ${ }^{b}$ Sri Sivasubramaniya Nadar College of Engineering, Department of Chemical Engineering, Kalavakkam, Tamil Nadu 603110, India.

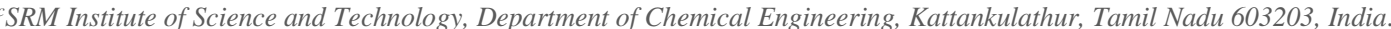

\begin{abstract}
Graphene synthesis has been carried out electrochemically with the source being graphite rods mechanically separated from waste model batteries. TEM, Raman spectroscopic analysis has been used to characterize the exfoliated graphene. Mesoporous graphene nanoparticle has been confirmed through BET analysis wherein the surface area and the pore diameter has been reported as $710.4 \mathrm{~m}^{2} / \mathrm{g}$ and $29.6 \AA$ respectively. The synthesized graphene nanoparticle is used to adsorb Methylene blue (MB) dye which is toxic by nature and the parameters studied are the dosage of adsorbent graphene, MB concentration, temperature and contact time. From UV, $\mathrm{XRD}$, and FTIR the adsorption of MB on graphene has been confirmed. The graphene's adsorption capacity at $30^{\circ} \mathrm{C}$ was $272 \mathrm{mg} / \mathrm{g}$. The adsorption followed fitted Temkin isotherm whereas the mechanism was pseudo-second-order. Physisorption and spontaneous adsorption process was reported by the thermodynamic study of the adsorption process.
\end{abstract}

Keywords: Methylene blue, water treatment, nano-graphene, Physisorption, electrochemical exfoliation, exothermic, Waste AA and AAA model batteries.

\section{INTRODUCTION}

Graphene is said to be a unique material having a lattice structure resembling a $2 \mathrm{D}$ honeycomb. Having a specific surface area of $\sim 2650 \mathrm{~m} 2 / \mathrm{g}$ graphene can be an efficient adsorbent [1,2]. They are considered unique due to their high thermal and electrical conductivities alongside strong mechanical and chemical properties [3-7]. Graphene synthesis is practiced using methods like CVD, direct exfoliation, electrochemical exfoliation, modified hummers method, hummers method, etc. Electrochemical exfoliation technique is more advantageous because of its less economy and also the low complex nature of the process. There exists a scope of improvement for large scale graphene production using the electrochemical technique [8,9]. Solution-based graphene exfoliation offers a solution for the production of quality graphene [10]. The waste batteries which are domestically used contain graphite rods which can be used for the exfoliation of graphene electrochemically. This has been carried out using sulfate based electrolytes with a disadvantage of agglomeration on the surface of graphene [11-13].

Dyes play a prime role in the textile industry since the Neolithic period and were used by food, leather and paper industries as well. Large volumes of textile wastewater along with the dyes when released to the environment can create an instability in the biota as they inhibit sunlight penetration. Metal ions when combined with dyes becomes toxic for aquatic life when they are adsorbed by them [14]. Conventional methods prove to have low success rate in separating the dyes from wastewater because of their high dye resistance. To remove the dyes from wastewater biological, physical and chemical methodologies are normally opted. Chemical methods like chlorination, coagulation, etc predominantly accumulate sludges in their concentrated form while the organic materials present in wastewater are degraded in biological treatment procedures. This makes physical separation of dyes vital and the best among the other methods. Adsorption, a physical process insensitive to toxic substances present and also proves to be cost effective technique in separating dyes from wastewater [15].

Methylene Blue (MB) which finds its wide application in dyeing industry leads to nausea, neurological problems, vomiting, and can be carcinogenic to humans $[16,17]$. This cationic dye is widely used to dye cotton, silk, wood, etc., as it has good color stability and solubility $[17,18]$. It has good stability towards heat and biodegradation [16]. Adsorbents, flocculants, and membranes are commonly used for the removal of MB [19]. The low cost adsorption technique which uses adsorbents like polymeric adsorbents [24], activated carbon [23], clay [22], and zeolite [21] is a successful commercial technique for wastewater treatment. Among the various adsorbents used, carbon reports high dye removal efficiency due to its rapid diffusion $[25,26]$. This has been a factor in choosing graphene (carbon allotrope) for this experimentation.

Graphene is found to be hydrophilic in nature making it a good choice as an adsorbent for dye removal. Many combinations of graphene with magnetic oxides, Pyrophosphate acid [29], hydrogels [28], $\mathrm{Fe}_{3} \mathrm{O}_{4}$ - mesoporous $\mathrm{SiO}_{2}$ [31], citric acid [33], thiosemicarbazide [34], carbon nanotube (G-CNT) [30], alginate composites [27], palygorskite- $\mathrm{TiO}_{2}$ [32], etc. adsorb dyes and heavy metals.
Graphene based adsorbents adsorb pyrophosphate acids, hydrogels, MB at 200 $\mathrm{mg} / \mathrm{g}$ [29], $87.63 \mathrm{mg} / \mathrm{g}$ [37], $714 \mathrm{mg} / \mathrm{g}$ [35,36] capacities respectively. Few other adsorbents namely thiosemicarbazide, mesoporous $\mathrm{SiO}_{2}$ nanocomposites, citric acid, CNT's, and $\mathrm{TiO}_{2}$ nano composites have their adsorption capacities at $596.642 \mathrm{mg} / \mathrm{g}$ [34], $178.49 \mathrm{mg} / \mathrm{g}$ [31], 315.5mg/g [33], $81.97 \mathrm{mg} / \mathrm{g} \mathrm{[30],} \mathrm{and}$ $6.710 \mathrm{mg} / \mathrm{g}[32]$ respectively.

Current research work represents a nanographene which is electrochemically exfoliated from graphite rods [38,39]. High capacity to adsorb dyes and high rates of adsorption are reported in adsorbents of nano size than large size adsorbent materials [32]. A novel graphene synthesized of nano size which is acid washed has been used in this study to adsorb methylene blue dye.

\section{Adsorption equations:}

The MB removal in percentage (\%R) can be evaluated using equation (1) and equation (2) is used to find out the equilibrium adsorption capacity $\left(\mathrm{q}_{\mathrm{e}}\right)$.

$$
\begin{aligned}
& q_{e}=\frac{\left(C_{0}-C_{e}\right) V}{m} \quad \text { Eqn..(1) } \\
& \% \mathrm{R}=\frac{\left(C_{0}-C_{e}\right) * 100}{C_{0}} \quad \text { Eqn..(2) }
\end{aligned}
$$

Wherein $\mathrm{V}$ - volume of the solution $(\mathrm{mL}), \mathrm{C}_{\mathrm{e}}$ - equilibrium concentration of MB dye solution ( $\mathrm{mg} / \mathrm{L}), \mathrm{C}_{0}$ - initial concentration of MB dye and $\mathrm{m}$ - graphene adsorbent mass $(\mathrm{g})$. The adsorption study is characterized using the isotherms mentioned below.

\section{Langmuir isotherm:}

A system where a single solute is adsorbed by an adsorbent in a monolayer fashion can be analyzed using Langmuir isotherm. This isotherm proposes that adsorption is favored by all the available sites of the adsorbent which possess equivalent energy. The relation between the active adsorption sites and the MB dye molecules at equilibrium concentration is represented in equation (3) and (4).

$$
\begin{aligned}
& \frac{C_{e}}{q_{e}}=\frac{1}{b q_{\max }}+\frac{C_{e}}{q_{\max }} \quad \text { Eqn..(3) } \\
& R_{L}=\frac{1}{\left(1+b C_{i}\right)} \quad \text { Eqn..(4) }
\end{aligned}
$$

where $C_{i}, \mathrm{q}_{\max }$, and $\mathrm{b}$ represents the initial concentration of the MB dye molecules, maximum capacity of adsorption, and the Langmuir constant respectively. $\mathrm{R}_{\mathrm{L}}$ is the separation factor that can predict the affinity of the sorbent and sorbate

\section{Freundlich isotherm:}

Multilayer adsorption of the solutes onto the adsorbent sites is the characteristic of Freundlich isotherm model. The specific bonding energy of the adsorptive sites is responsible for the adsorption of the adsorbate onto the 
adsorbent. The parameters involved in the adsorption of a solute on an heterogeneous adsorbent surface can be found using equation (5).

$$
\log q_{e}=\frac{1}{n} \log C_{e}+\log K_{f} \quad \text { Eqn..(5) }
$$

where the concentration at its equilibrium is $\mathrm{C}_{\mathrm{e}}$ in $\mathrm{mg} / \mathrm{L}$, adsorption capacity $K f$, amount of MB that is adsorbed when a unit mass of the graphene adsorbent is used under equilibrium conditions is $\mathrm{q}_{\mathrm{e}}(\mathrm{mg} / \mathrm{g}), \mathrm{n}$ - intensity of adsorption.

\section{Temkin isotherm:}

Temkin isotherm relates the effect of heat of adsorption on the interaction of the solute and the adsorbent which is at the solid state (heterogeneous). The quantity of heat required to adsorb is proportional to the adsorbent's active sites. Temkin isotherm can be represented as equation (6).

$$
q_{e}=B_{T} \ln A_{T}+B_{T} \ln C_{e} \quad \text { Eqn..(6) }
$$

wherein the amount of heat necessary for the adsorption process in related to the Temkin constant $\left(\mathrm{B}_{\mathrm{T}}\right), \mathrm{A}_{\mathrm{T}}$ in $1 / \mathrm{mg}$ is the binding constant at equilibrium. From the plot $\ln C_{e}$ vs $q_{e}$, the slope and intercept values are determined by $\mathrm{B}_{\mathrm{T}}$ and $\mathrm{A}_{\mathrm{T}}$ respectively.

\section{Dubinin and Radushkevich Isotherm}

$$
\begin{aligned}
& \ln q_{e}=\ln q_{m}-\beta \varepsilon^{2} \quad \text { Eqn..(7) } \\
& \varepsilon=\frac{R T}{\ln \left[1+\left(\frac{1}{C_{e}}\right)\right]} \quad \text { Eqn..(8) }
\end{aligned}
$$

where $\beta$ - activity coefficient and $\varepsilon$ - polanyi potential are determined. $q_{e}$ and $q_{m}$ represents the adsorbed MB dye per adsorbent dosage and monolayer saturation capacity in $\mathrm{mg} / \mathrm{g}$ respectively. $\ln \varepsilon^{2} \mathrm{vs} q_{e}$ is plotted and the intercept and slope are determined using $q_{m}$ and $\beta$ respectively.

\section{Adsorption Kinetics:}

An effluent/water treatment plant can be designed incorporating the mechanism of adsorption and also the kinetics. Adsorption mechanism depends on the properties of the adsorbent and the solute molecules which can be explained by the models below.

Pseudo-first-order model relates the unoccupied adsorptive sites of the adsorbent, rate at which adsorption occurs. Under equilibrium condition, the relation between the adsorptive sites that is occupied and the sites available for adsorption is expressed by the Pseudo-second-order model. In the absence of lateral interactions between energetically heterogeneous adsorbent and the adsorbate, Elovich model can be applied. Amount of solute molecules present and the number of adsorptive sites available determine the rate of adsorption. Kinetic equations are represented from equation (9) to (12).

$$
\begin{aligned}
& \text { Pseudo-first-order kinetics: } \ln \left(q_{e}-q_{t}\right)=\ln q_{e}-K_{1} t \quad \text { Eqn..(9) } \\
& \text { Pseudo-second-order kinetics }: \frac{t}{q_{t}}=\frac{1}{K_{2} q_{e}^{2}}+\frac{t}{q_{e}} \quad \text { Eqn..(10) } \\
& \text { Intraparticle diffusion : } q_{t}=K_{3}\left(t^{\frac{1}{2}}\right)+c \quad \text { Eqn..(11) } \\
& \text { Elovich : } q_{t}=\frac{1}{\beta} \ln (\alpha \beta)+\frac{1}{\beta} \ln (t) \quad \text { Eqn..(12) }
\end{aligned}
$$

wherein $K_{1}, K_{2}$, and $K_{3}$ are the constants from equation (9) to (11) belonging to pseudo first order, pseudo second order, and intraparticle diffusion models. A $\mathrm{q}_{\mathrm{t}}$ vs. $\ln (\mathrm{t})$ plot is done for calculating the intercept $((1 / \beta) \ln (\alpha \beta))$ and slope $((1 / \beta))$. B - desorption constant, $\alpha$-adsorption rate at the initial stage.

\section{EXPERIMENTAL}

\section{Chemicals and Materials:}

Waste AA and AAA model batteries, electrochemical setup, Regulated power supply system, $\mathrm{MgSO}_{4}$, mild steel electrode, Membrane filter (Novamem PEEK5), diethyl ether, distilled and deionized water, $\mathrm{HCl}$, ethanol, methylene blue (MB) dye.

\section{Graphene powder synthesis:}

Discharged AA and AAA batteries has been used as a graphite source. Graphite in the form of rods present in the batteries are separated mechanically. Hydrochloric acid has been used as a pretreating agent to remove any impurities present. The electrolytic setup used consists of mild steel and graphite rods as anode and cathode respectively, $1 \mathrm{M}$ magnesium sulphate as electrolyte, an RPS system to regulate $10 \mathrm{~V}(1 \mathrm{~A})$ power supply. Exfoliation takes place in the electrolytic setup and the wet graphene exfoliated is vacuum filtered using Novamem filter and is washed with deionized water $(30 \mathrm{ml})$ followed by $30 \mathrm{ml}$ of $\mathrm{HCl}$, and $30 \mathrm{ml}$ ethyl alcohol to remove the impurities. Sulfate ions along with metal ions are removed when washed with deionized water. Alcohol wash removes any magnesium oxide produced whereas coagulation of graphene can be prevented by ether wash along with the removal of any acids and oxides present on graphene's external surface. The graphene powder is further dried under vacuum and used for further studies.

\section{Adsorption studies:}

Various dye concentrations ranging from $5,10,15,20$, and $25 \mathrm{mg} / \mathrm{L}$ is prepared by dissolving Methylene blue $\left(\mathrm{Cl}_{6} \mathrm{H}_{18} \mathrm{ClN}_{3} \mathrm{~S}\right)$ dye in distilled water. $100 \mathrm{~mL}$ of $25 \mathrm{mg} / \mathrm{L} \mathrm{MB}$ solution is added to 6 different conical flasks which contains 10 , $20,30,40,50$, and $60 \mathrm{mg}$ of graphene powder. These 6 conical flasks are continuously stirred in a shaker for one hour at $30^{\circ} \mathrm{C}$ to find out the optimum graphene required for the adsorption process. $40 \mathrm{mg}$ graphene reports a maximum of $92.4 \% \mathrm{MB}$ dye removal and this graphene dose is used in our further experimentations. Different concentrations of MB dye say 5, 10, 15, 20 and $25 \mathrm{mg} / \mathrm{L}$ are poured to 5 different conical flasks containing graphene powder of $40 \mathrm{mg}$. These flasks are stirred well using a shaker and $10 \mathrm{ml}$ of the solution is taken out of the flask for every 10 minutes and filtered to determine the final dye concentration using UV-Spectrophotometer. The above procedure is repeated for $20^{\circ} \mathrm{C}, 30^{\circ} \mathrm{C}, 40^{\circ} \mathrm{C}, 50^{\circ} \mathrm{C}$, and $60^{\circ} \mathrm{C}$ to report the temperature effects of the adsorption studies.

\section{RESULT AND DISCUSSION}

\section{Graphene powder:}

A Micro-Raman Spectrometer, HORIBA France, LABRAM HR Evolution is used to analyse the graphene synthesized. Graphene presence in confirmed by the peaks inferred from figure 1 analyzed at $532 \mathrm{~nm}[40,41]$. The $\sim 1350 \mathrm{~cm}^{-1} \mathrm{D}$ band peak infers to the highly reactive carboxyl groups. These weak groups are responsible for graphene's disorder near its edges $[42,43]$. The $\sim 1580 \mathrm{~cm}^{-1} 2 \mathrm{D}$ peak represents a sensitive first order double degenerative optical vibrational $\left(\mathrm{E}_{2 \mathrm{~g}}\right)$ graphene. A sharp $2710 \mathrm{~cm}^{-1}$ peak attributes a monolayer graphene which can be confirmed from the TEM image (Figure 1). Nanographene can be inferred from the morphological image represented in Figure 1.

Figure 2 represents the Nitrogen adsorption-desorption analysis curve for the graphene nanoparticle. The graphene reported to have the pore volume, BET specific surface area, and pore diameter as $0.572 \mathrm{cc} / \mathrm{g}, 710.4 \mathrm{~m}^{2} / \mathrm{g}$, and $29.6 \AA$ respectively confirming a mesoporous graphene which is ideal for carrying out an adsorption process. The graphene adsorbent samples after the MB adsorption studies $(10,20,30,40,50 \mathrm{mg} / \mathrm{l})$ have been analyzed through an X-Ray Diffractometer (PANalytical, Netherlands) with $0.154 \mathrm{~nm}$ wavelength, having $0.0456 \mathrm{deg} / \mathrm{min}$ scanning rate. The anode material used is copper. Figure 3 represents XRD analysis of 5 different samples of graphene after MB adsorption $(10,20,30,40,50 \mathrm{mg} / \mathrm{l})$. From figure 3 , all the MB adsorbed graphene powder exhibit strong peaks at $26^{\circ}$ and $21^{\circ}$. The peak at $2 \theta=\sim 21^{\circ}(220)$ informs us that the adsorbents are multilayered [44, 45, 46]. This may be attributed to the multilayer deposition of MB over the graphene powder.

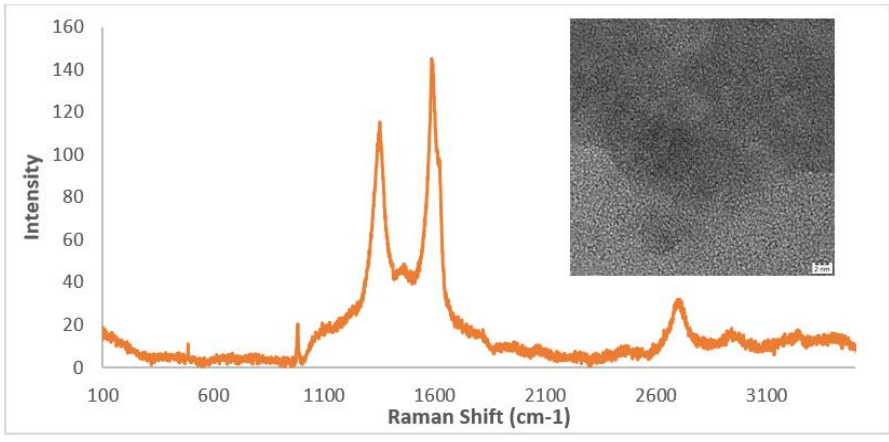

Figure 1. Micro-Raman spectra of the as-prepared graphene. HRTEM image of the graphene powder at $2 \mathrm{~nm}$ (inside). 
Presence of amorphous graphene powder can be inferred from $26^{\circ}(122)$ and this represents the crystal plane of graphene $[41,47,48,49,50] .2 \theta=\sim 42^{\circ}(122)$ peak represents few graphene crystals in all the adsorbents except for $10 \mathrm{mg} / \mathrm{l}$ [50]. A peak at $\sim 24^{\circ}$ is observed for 2 graphene samples $(20$ and $50 \mathrm{mg} / \mathrm{L}$ Methylene Blue concentration) confirming the presence of oxygen functional groups [51].

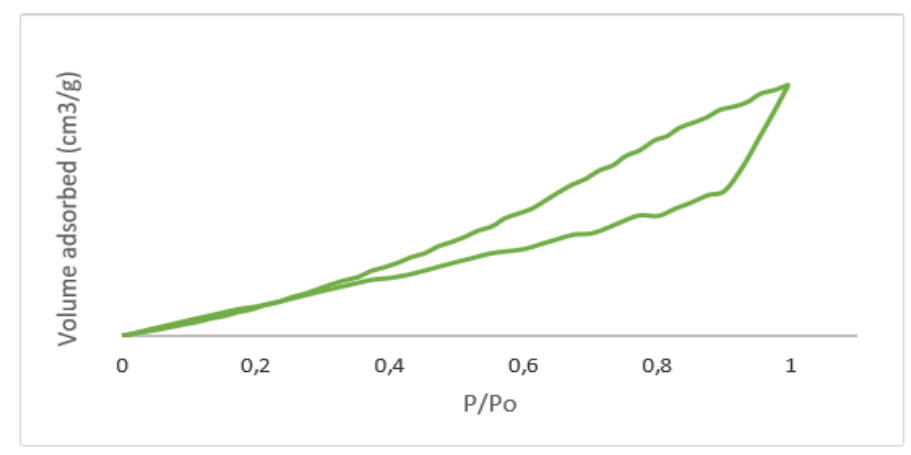

Figure 2. Nitrogen adsorption-desorption isotherm for graphene.

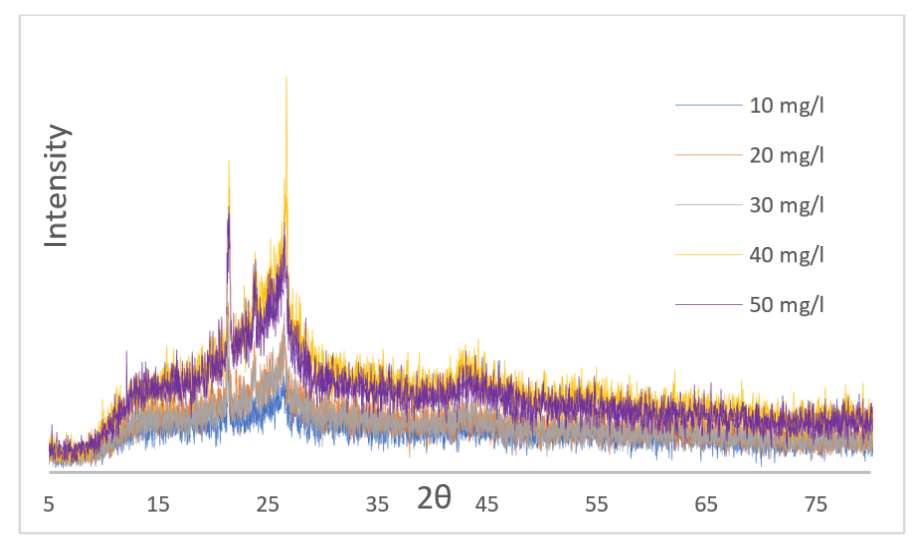

Figure 3. XRD analysis of graphene powder after adsorption for different MB concentrations.

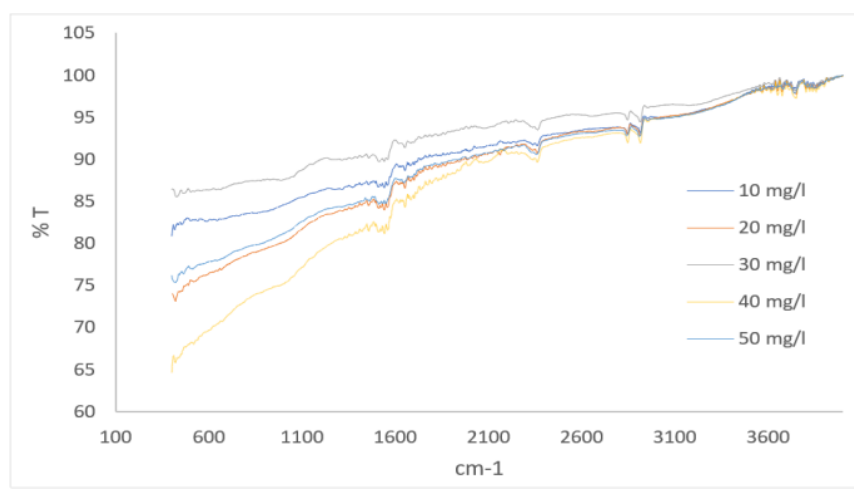

Figure 4. FTIR analysis of various graphene samples after MB adsorption.

Table. 1 FTIR vibration peaks for different graphene samples after adsorption

\begin{tabular}{|c|c|c|c|c|c|c|c|c|}
\hline & $\mathbf{1 0}$ & $\mathbf{2 0}$ & $\mathbf{3 0}$ & $\mathbf{4 0}$ & $\mathbf{5 0}$ & $\begin{array}{c}\text { Functional } \\
\text { group }\end{array}$ & $\begin{array}{c}\text { Compound } \\
\text { class }\end{array}$ & Ref. \\
\cline { 2 - 8 } & & 3649.4 & & 3650.5 & & O-H stretch & alcohol & $\begin{array}{l}\text { Kordi et al. } \\
2019\end{array}$ \\
\cline { 2 - 8 } \\
$\begin{array}{l}\text { Frequency } \\
\left(\mathbf{c m}^{-1}\right)\end{array}$ & 2912.6 & 2913.5 & 2912.6 & $2845,2913.5$ & 2909.7 & C-H stretch & aliphatic & $\begin{array}{l}\text { Ruoff 2008c; } \\
\text { Mishra and } \\
\text { Ramaprabhu } \\
2011 \mathrm{c}\end{array}$ \\
\cline { 2 - 8 } & 1569.1 & 1570.4 & 1563.3 & 1559.5 & 1586.7 & C-C stretch & aromatics & Qin et al. 2020a \\
\hline
\end{tabular}

The functional groups present in the graphene adsorbents after adsorption are analyzed by FTIR Spectrometer, IRTRACER 100, Shimadzu. In all the adsorbents (table 1), a C-H aliphatic bond (stretch) is inferred from the peak around $2900 \mathrm{~cm}^{-1}[9,51]$. From figure 4, presence of oxidized graphene in minimal quantity is inferred by a peak around $1600 \mathrm{~cm}^{-1}[48,52,53]$.

\section{Effect of contact time}

Figure (5) represents the effect of contact time to \% removal of MB (c), MB concentration (b), $\mathrm{pH}$ vs \% removal for $10 \mathrm{mg} / \mathrm{l} \mathrm{MB} \mathrm{(d),} \mathrm{and} \mathrm{the} \mathrm{MB} \mathrm{adsorbed} \mathrm{at}$ $30^{\circ} \mathrm{C}$ (d) which can be obtained using equation (1) and (2). Adsorption of MB onto graphene takes place in 3 stages as seen in Figure 5. The first stage takes place before $\sim 20$ minutes which is because of the MB dye transfer onto the adsorbent graphene's external surface. Second stage is observed between $\sim 20$ to $\sim 60$ minutes where the dye diffuses (internal diffusion) into the adsorptive sites of graphene. The equilibrium is reached in less than 60 minutes which is the third stage of the sorption process. Adsorption increase in the first 30 minutes is attributed to the $\pi$ - $\pi$ interactions linking MB to the aromatic ring of the adsorbent graphene and furthermore the freely available adsorptive sites of graphene also assists. The saturation of the adsorption sites occurs after 30 minutes slowing down the rate of adsorption and this is attributed to the external diffusion that controls MB adsorption into the planar surface of graphene [56].

It is observed that within 60 minutes of adsorption, the percentage MB dye removal attains $90 \%$ for all the dye concentrations except for $5 \mathrm{mg} / \mathrm{L}$. For $5 \mathrm{mg} / \mathrm{l}$ of the MB solution $90 \% \mathrm{MB}$ dye removal is attained in 10 minutes. Almost 100\% MB dye removal is achieved in 90 minutes when the adsorption takes place at $20^{\circ} \mathrm{C}, 30^{\circ} \mathrm{C}$, and 100 minutes for $40^{\circ} \mathrm{C}, 50^{\circ} \mathrm{C}$. From Figure $5 \mathrm{c}$, it is noted that as the temperature increases the adsorption time also increases. Temperature studies indicate better adsorption at $30^{\circ} \mathrm{C}$ and the trend of effective adsorption temperature is $30^{\circ} \mathrm{C}>20^{\circ} \mathrm{C}>40^{\circ} \mathrm{C}>50^{\circ} \mathrm{C}$. It is inferred that as the temperature increases adsorption decreases and chemisorption may occur [55]. Experimentations on the effect of $\mathrm{pH}$ is done using $10 \mathrm{mg} / \mathrm{L} \mathrm{MB}$ concentration and an adsorbent mass of $40 \mathrm{mg}$ at $30^{\circ} \mathrm{C}$. $\mathrm{pH}$ has been varied from 5 to 7 using Dil. HCl. Figure $5 \mathrm{~d}$ shows that a pH of 6.5 removes $99.9 \%$ of MB dye. Results indicate that the adsorption decreases as $\mathrm{pH}$ decreases.

\section{Adsorption isotherms:}

Methylene blue dye - graphene interactions has been studied using Langmuir isotherm, Freundlich isotherm, Temkin isotherm, and Dubinin-Radushkevich isotherm and equations 3 to 8 are used to determine the maximum adsorption capacities. Linearized form of mathematical equations were used to study the mechanism of graphene-MB adsorption at various temperatures say $20^{\circ} \mathrm{C}, 30^{\circ} \mathrm{C}, 40^{\circ} \mathrm{C}, 50^{\circ} \mathrm{C}, 60^{\circ} \mathrm{C}$. Adsorption isotherms are found to be linear for very low solute concentrations. The datas obtained do not fit in Langmuir isotherm (figure $6 \mathrm{c}$ ), the calculated $\mathrm{b}^{*} \mathrm{C}_{\mathrm{e}}$ value is more than one [58]. From table $2, \mathrm{q}_{\mathrm{e}, \max }$ is found to be $272 \mathrm{mg} / \mathrm{g}$ at $30^{\circ} \mathrm{C}$ and is better than many other adsorbents (table 3 and 4). Equation (4) is used to find out the adsorption nature. $R_{L}$ values are found to increase with temperature and for $30^{\circ} \mathrm{C}, R_{L}$ value is 0.47 . As the $R_{L}$ value lies within the range of 0 to 1 , the adsorption is favorable and will be monolayer in nature.

The surface of adsorption can be heterogeneous [59]. Based on the $\mathrm{R}^{2}$ values mentioned in table 2, it can be concluded that the adsorption fits well with Freundlich isotherm model. A maximum of $22 \mathrm{mg} / \mathrm{g}$ at $30^{\circ} \mathrm{C}$ was the $\mathrm{K}_{\mathrm{f}}$ values obtained (table 2) indicating a favorable adsorption process. It has been noted that the $\mathrm{K}_{\mathrm{f}}$ values are in a decreasing trend as the adsorption proceeds towards $60^{\circ} \mathrm{C}$. The $\mathrm{n}$ values mentioned in table 2 are found to be lesser than 1 deducing the presence chemical bonding during the adsorption process [60]. The $\mathrm{R}^{2}$ values for Temkin isotherm indicate the adsorption of MB may be based on heat [1, 61]. Comparing the $\mathrm{R}^{2}$ values the adsorption mechanism best fits in the Temkin model $\left(R^{2}=0.9971\right)$ with an efficient binding energy $\left(A_{T}\right)$ of $224 \mathrm{~L} / \mathrm{g}$ for $30^{\circ} \mathrm{C}$. As the temperature increases, the $\mathrm{B}_{\mathrm{T}}$ value decreases from $0.06 \mathrm{~J} / \mathrm{mol}$ to $0.012 \mathrm{~J} / \mathrm{mol}$. Dubinin and Radushkevich Isotherm is used to determine the mean adsorption energy. A strong adsorption process is indicated with the $\mathrm{E}$ value of 8.94 $\mathrm{KJ} / \mathrm{mol}\left(\mathrm{R}^{2}=0.9433\right)$ at $40^{\circ} \mathrm{C}[18]$. 

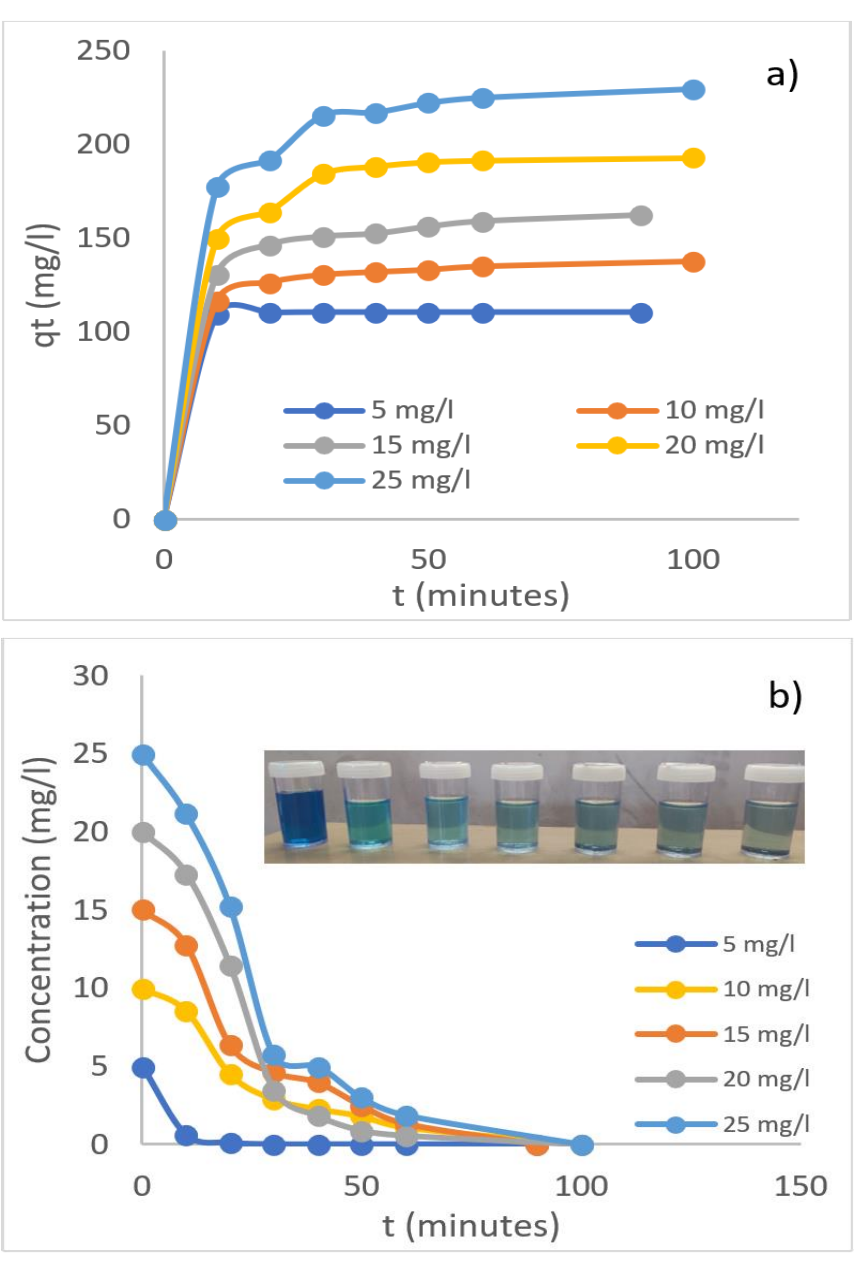
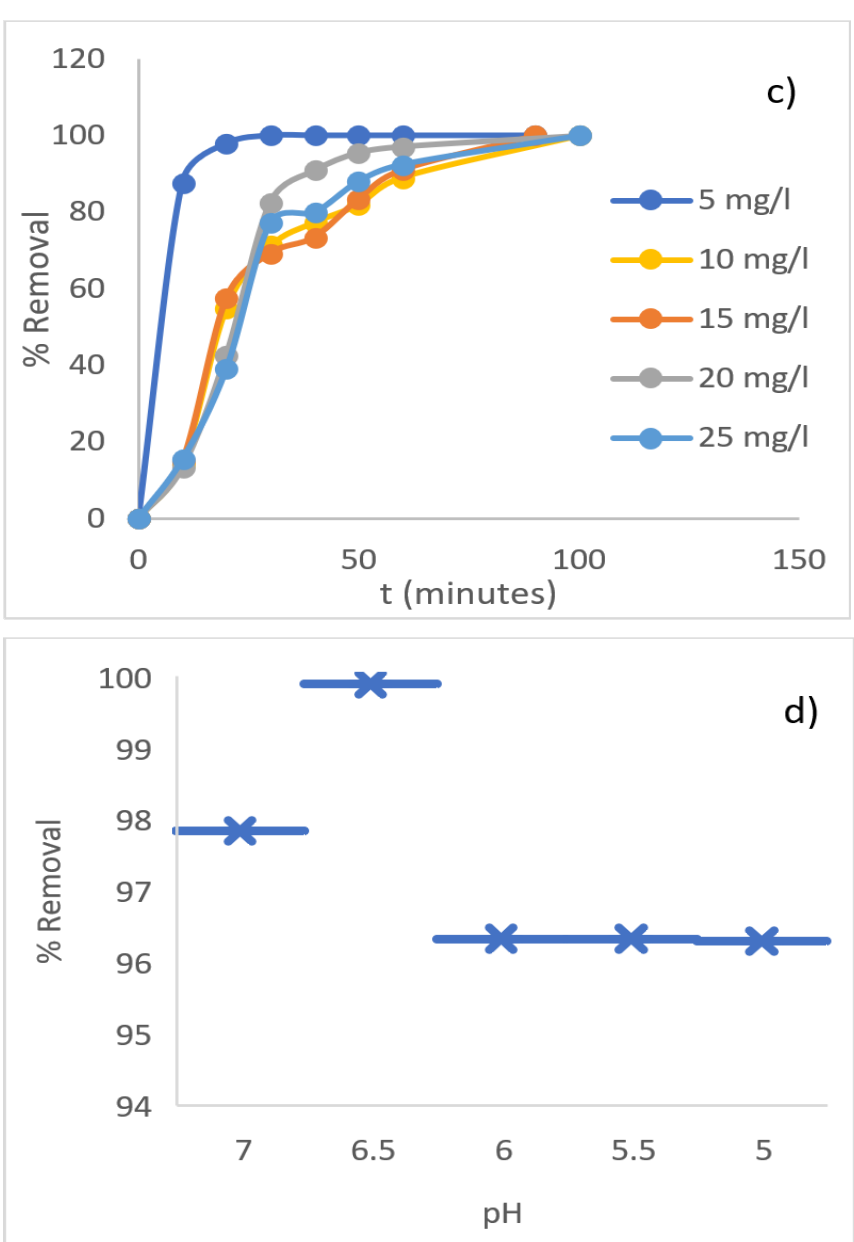

Figure 5. Effect of contact time vs $\mathrm{Q}_{\mathrm{t}}$ at $30^{\circ} \mathrm{C}$ (a), $\mathrm{t}$ vs $\mathrm{MB}$ concentration at $30^{\circ} \mathrm{C}$ (b) $\mathrm{MB}$ samples after adsorption (inside), $\mathrm{t}$ vs $\%$ removal at $30^{\circ} \mathrm{C}(\mathrm{c}) \mathrm{pH}$ vs $\%$ removal for $10 \mathrm{mg} / \mathrm{l} \mathrm{MB}$ dye concentration at $30^{\circ} \mathrm{C}(\mathrm{d})$.
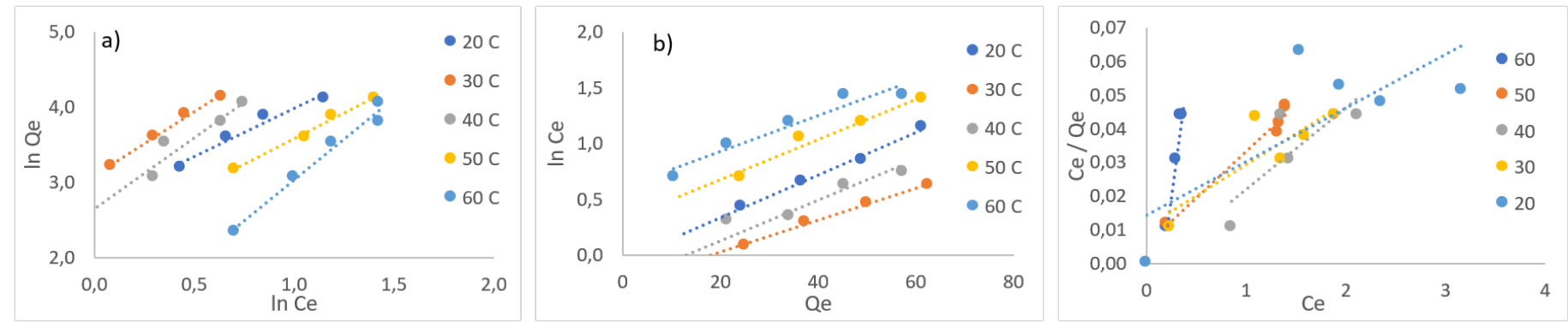

Figure 6. Adsorption isotherms of MB over graphene powder. Freundlich Isotherm (a) Temkin isotherm (b) Langmuir Isotherm (c).

Table 2. Adsorption isotherm parameters for Methylene blue adsorption on graphene

\begin{tabular}{|c|c|c|c|c|c|c|}
\hline \multirow{2}{*}{\multicolumn{2}{|c|}{ Adsorption Isotherms }} & \multicolumn{5}{|c|}{ Temp. $\left({ }^{0} \mathrm{C}\right)$} \\
\hline & & 20 & 30 & 40 & $\mathbf{5 0}$ & 60 \\
\hline \multirow[t]{4}{*}{ Langmuir } & $\mathrm{K}_{\mathrm{L}}(\mathrm{L} / \mathrm{mg})$ & 0.026 & 0.312 & 0.284 & 0.111 & 0.032 \\
\hline & $\mathrm{R}_{\mathrm{L}}$ & 0.718 & 0.473 & 0.891 & 0.935 & 0.782 \\
\hline & $\mathrm{q}_{\max }(\mathrm{mg} / \mathrm{g})$ & 159.565 & 272.348 & 220.160 & 175 & 173.070 \\
\hline & $\mathrm{R}^{2}$ & 0.983 & 0.938 & 0.724 & 0.685 & 0.575 \\
\hline \multirow[t]{3}{*}{ Freundlich } & $\mathrm{n}$ & 0.590 & 0.782 & 0.731 & 0.565 & 0.529 \\
\hline & $\mathrm{K}_{\mathrm{f}}(\mathrm{mg} / \mathrm{g})(\mathrm{L} / \mathrm{mg})^{1 / \mathrm{n}}$ & 15.034 & 22.085 & 14.107 & 10.151 & 9.117 \\
\hline & $\mathrm{R}^{2}$ & 0.957 & 0.991 & 0.963 & 0.988 & 0.980 \\
\hline \multirow[t]{3}{*}{ Temkin } & $\mathrm{B}_{\mathrm{T}}(\mathrm{J} / \mathrm{mol})$ & 0.048 & 0.060 & 0.046 & 0.043 & 0.012 \\
\hline & $\mathrm{A}_{\mathrm{T}}(\mathrm{L} / \mathrm{g})$ & 221.868 & 224.493 & 199.338 & 173.477 & 131.319 \\
\hline & $\mathrm{R}^{2}$ & 0.9907 & 0.9971 & 0.9203 & 0.9642 & 0.9284 \\
\hline \multirow{4}{*}{ Dubinin - Radushkevich } & $\mathrm{q}_{\mathrm{d}}(\mathrm{mg} / \mathrm{g})$ & 72.3 & 88.5 & 60.5 & 48.2 & 40.8 \\
\hline & $\mathrm{R}^{2}$ & 0.9201 & 0.7783 & 0.9433 & 0.9185 & 0.9433 \\
\hline & $\mathrm{E}(\mathrm{kJ} / \mathrm{mol})$ & 10.45 & 12.56 & 8.94 & 8.45 & 6.91 \\
\hline & $\beta\left(\mathrm{mol}^{2} / \mathrm{kJ}^{2}\right)$ & 0.0988 & 0.1113 & 0.0141 & 0.0133 & 0.0093 \\
\hline
\end{tabular}


Table 3. Comparison of dye removal efficiency of various adsorbents with the current study

\begin{tabular}{|c|c|c|c|c|}
\hline Adsorbent & Dye concentration / Volume & Time (min) & Dye removal (\%) & Ref \\
\hline Graphene powder (GP2) / $40 \mathrm{mg}$ & $5 \mathrm{mg} / \mathrm{L}(100 \mathrm{ml})$ & 30 & 99.96 & This work \\
\hline$\beta-\mathrm{MnO}_{2}$ microrods / $40 \mathrm{mg}$ & $40 \mathrm{mg} / \mathrm{L}(100 \mathrm{ml})$ & 40 & 85 & Yu et al. 2014 \\
\hline $\mathrm{MnO}_{2} @ \mathrm{SiO}_{2} \mathrm{NFM} / 50 \mathrm{mg}$ & $10 \mathrm{mg} / \mathrm{L}(100 \mathrm{ml})$ & 40 & 95 & Wang et al. 2017 \\
\hline $\mathrm{GO} / \mathrm{Mn}_{3} \mathrm{O}_{4} / 10 \mathrm{mg}$ & $50 \mathrm{mg} / \mathrm{L}(50 \mathrm{ml})$ & 50 & 91 & Li et al. 2015 \\
\hline $\mathrm{MnO}_{3} \mathrm{O}_{4} / \mathrm{NG}-0.5 / 5 \mathrm{mg}$ & $50 \mathrm{mg} / \mathrm{L}(25 \mathrm{ml})$ & 60 & 95 & Fan et al. 2018 \\
\hline $\mathrm{Fe}_{3} \mathrm{O}_{4} @$ PDA- $\mathrm{MnO}_{2} / 5 \mathrm{mg}$ & $40 \mathrm{mg} / \mathrm{L}(25 \mathrm{ml})$ & 30 & 94 & Qin et al. 2020a \\
\hline
\end{tabular}

Table 4. Adsorption capacities of various graphene based adsorbents in methylene blue dye removal [Choudhury and Balasubramanian 2014]

\begin{tabular}{|c|c|c|c|c|c|}
\hline Adsorbent & Conc. & $\mathbf{p H}$ & $\mathbf{T}(\mathbf{K})$ & Contact time (h) & Adsorption capacity (mg/g) \\
\hline Graphene (this study) & 5 to $25 \mathrm{mg} / \mathrm{l}$ & & 303 & 1 & 272 \\
\hline Graphene & $20-120 \mathrm{mg} / \mathrm{l}$ & 10.0 & 333 & & 204.08 \\
\hline Graphene & $5 \mathrm{mg} / \mathrm{l}$ & - & 303 & 96 & 1520 \\
\hline Graphene sponge & $2 \times 10^{-4} \mathrm{~mol} / \mathrm{l}$ & - & 298 & 4 & 184 \\
\hline GO & $0.188-1.000 \mathrm{~g} / 1$ & 6.0 & 298 & 1 & 714 \\
\hline GO & $0.33-3.3 \mathrm{mg} / \mathrm{l}$ & 7.0 & 293 & 2 & 1939 \\
\hline GO & $10-50 \mathrm{mg} / \mathrm{l}$ & 10.0 & - & - & 17.3 \\
\hline GO & $40-120 \mathrm{mg} / \mathrm{l}$ & 6.0 & 298 & 5 & 240.65 \\
\hline PES/GO & $50-250 \mu \mathrm{mol} / 1$ & 7.0 & $303 \pm 1$ & 60 & 62.50 \\
\hline $\mathrm{GO} /$ calcium alginate & $30-80 \mathrm{mg} / \mathrm{l}$ & - & 298 & 5 & 181.81 \\
\hline Graphene/magnetite & $10-25 \mathrm{mg} / \mathrm{l}$ & - & 298 & - & 43.82 \\
\hline Magnetic $\beta$-cyclodextrin- chitosan/GO & - & - & 298 & - & 84.32 \\
\hline Graphene-CNT & $10-30 \mathrm{mg} / \mathrm{l}$ & - & - & 3 & 81.97 \\
\hline $\mathrm{Fe} 3 \mathrm{O} 4-\mathrm{SiO} 2-\mathrm{GO}$ & - & - & 318 & & 102.6 \\
\hline Graphene-chitosan & $0-80 \mathrm{mg} / \mathrm{l}$ & 6.5 & $294 \pm 1$ & 58 & 390 \\
\hline Graphene/c-MWCNT & $20 \mathrm{mg} / \mathrm{l}$ & - & Room temp. & - & 191.0 \\
\hline Magnetite/graphene & - & - & $298 \pm 0.5$ & - & 45.27 \\
\hline RGO-titanate & $10 \mathrm{mg} / \mathrm{l}$ & - & - & - & 83.26 \\
\hline RGO-based hydrogel & $0.5-10 \mathrm{mg} / 1$ & 6.4 & 298 & 2 & 7.85 \\
\hline Magnetic chitosan/GO & $50-100 \mathrm{mg} / \mathrm{l}$ & - & $303 \pm 0.2$ & - & 180.83 \\
\hline
\end{tabular}
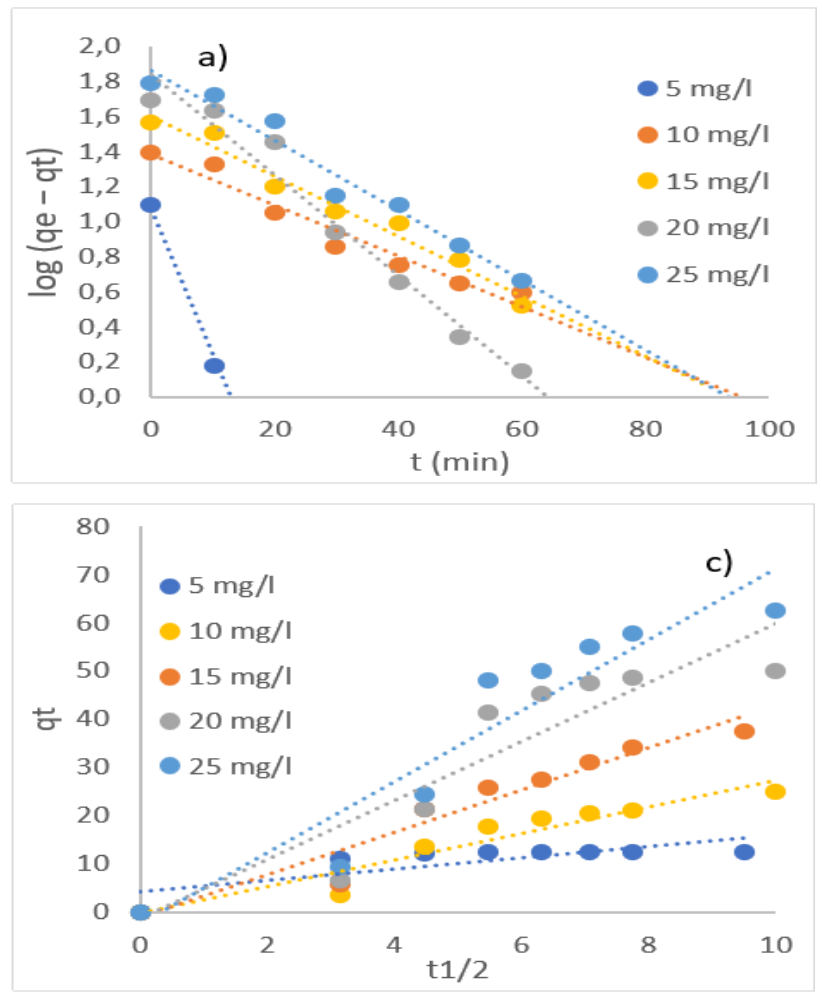
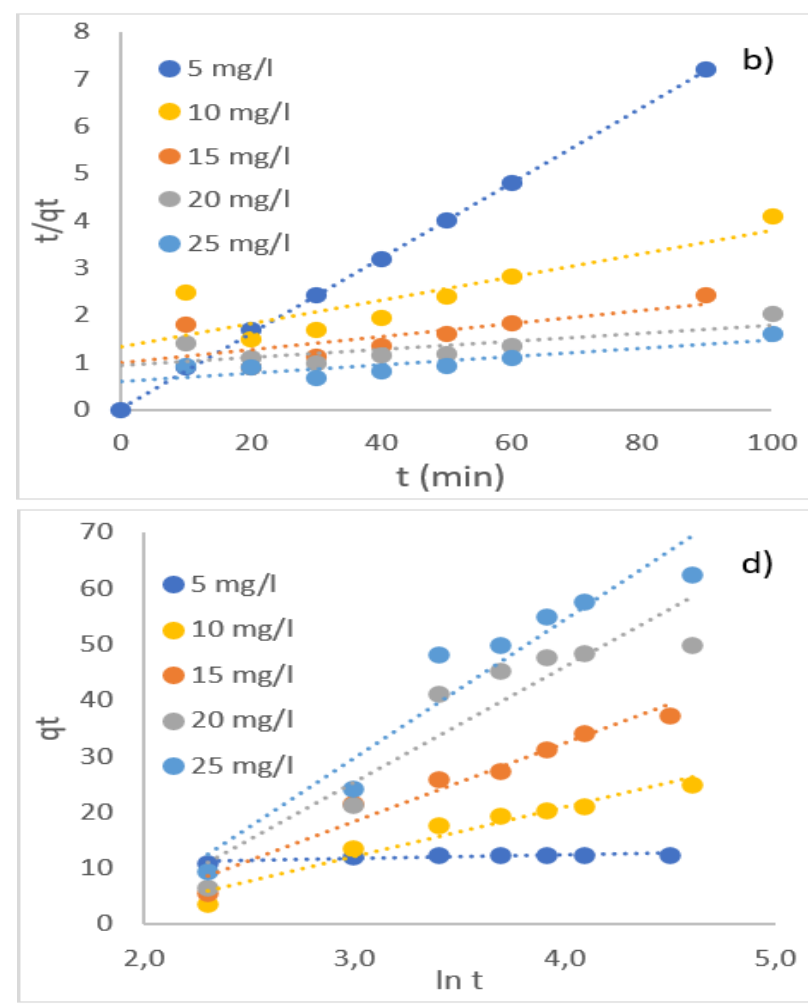

Figure 7. The adsorption capacity of graphene on Methylene blue (a) Pseudo-first-order kinetics $\left(30^{\circ} \mathrm{C}\right)$, (b) Pseudo-second-order kinetics $\left(20^{\circ} \mathrm{C}\right)$, (c) Intraparticle diffusion $\left(30^{\circ} \mathrm{C}\right),(\mathrm{d})$ Elovich Kinetics $\left(30^{\circ} \mathrm{C}\right)$. 
Table 5 reports the $\mathrm{q}_{\mathrm{e}, \max }$ values, $159.21 \mathrm{mg} / \mathrm{g}\left(\mathrm{R}^{2}=0.9692\right)$ and $231.12 \mathrm{mg} / \mathrm{g}\left(\mathrm{R}^{2}=0.9239\right)$ for pseudo-first-order kinetic model and pseudo-second-order kinetic model respectively. With a rate constant $\left(\mathrm{k}_{2}\right)$ value of $0.00021 \mathrm{~g} / \mathrm{mg} / \mathrm{min}$ and on comparing $\mathrm{q}_{\mathrm{e}}$ and $\mathrm{R}^{2}$ values, perfect fit is obtained for pseudo-second-order kinetics (figure 7) and this is the rate limiting step [67]. Elovich model is evaluated with $0.26 \mathrm{~g} / \mathrm{mg}$, and $19.34 \mathrm{mg} / \mathrm{g} / \mathrm{min}^{2}$ as the maximum $\beta\left(20^{\circ} \mathrm{C}\right)$ and $\alpha\left(60^{\circ} \mathrm{C}\right)$ values respectively.

Table 5. Kinetic parameters for graphene - MB adsorption

\begin{tabular}{|c|c|c|c|c|c|c|c|c|c|c|c|c|c|}
\hline \multirow{2}{*}{$\begin{array}{c}\mathrm{C}_{0} \\
(\mathrm{mg} / \mathrm{l})\end{array}$} & \multirow[b]{2}{*}{$\begin{array}{c}\mathbf{q}_{\mathrm{e},, \exp } \\
(\mathbf{m g} / \mathrm{g})\end{array}$} & \multicolumn{3}{|c|}{ Pseudo - first - order } & \multicolumn{3}{|c|}{ Pseudo - second - order } & \multicolumn{3}{|c|}{ Intraparticle diffusion } & \multicolumn{3}{|c|}{ Elovich } \\
\hline & & $\begin{array}{c}\mathrm{q}_{\mathrm{e}, \mathrm{cal}} \\
(\mathrm{mg} / \mathrm{g})\end{array}$ & $\begin{array}{c}\mathbf{k}_{1} \\
(1 / \mathrm{min})\end{array}$ & $\mathbf{R}^{2}$ & $\begin{array}{c}\mathrm{q}_{\mathrm{e}, \mathrm{cal}} \\
(\mathrm{mg} / \mathrm{g})\end{array}$ & $\begin{array}{c}\mathrm{k}_{2} \\
\left(\mathrm{~g} / \mathrm{mg} \cdot \mathrm{min}^{-1}\right)\end{array}$ & $\mathbf{R}^{2}$ & $\begin{array}{c}\mathrm{C} \\
(\mathrm{mg} / \mathrm{g})\end{array}$ & $\frac{k_{3}}{(\mathrm{mg} /(\text { g.min } 0.5))}$ & $\mathbf{R}^{2}$ & $\underset{(\mathrm{g} / \mathrm{mg})}{\boldsymbol{\beta}}$ & $\begin{array}{c}\alpha \\
(\mathrm{mg} / \mathrm{g} \\
\mathrm{min})\end{array}$ & $\mathbf{R}^{2}$ \\
\hline 5 & 110.38 & 73.29 & 0.0375 & 0.9967 & 107.32 & 0.0104 & 0.9998 & 4.4989 & 0.521 & 0.9835 & 0.26 & 3.391 & 0.9969 \\
\hline 10 & 137.45 & 99.57 & 0.0332 & 0.9538 & 129.47 & 0.0042 & 0.9998 & 3.2107 & 1.042 & 0.937 & 0.21 & 4.559 & 0.9697 \\
\hline 15 & 162.34 & 119.56 & 0.0461 & 0.9596 & 152.18 & 0.0039 & 0.9239 & 2.0815 & 1.750 & 0.9326 & 0.07 & 13.653 & 0.9578 \\
\hline 20 & 192.74 & 143.09 & 0.1911 & 0.9832 & 193.93 & 0.0037 & 0.9921 & 3.421 & 2.279 & 0.9325 & 0.05 & 19.349 & 0.9741 \\
\hline 25 & 229.62 & 159.21 & 0.3273 & 0.9692 & 231.12 & 0.0021 & 0.9239 & 2.2332 & 2.739 & 0.9274 & 0.08 & 12.528 & 0.9264 \\
\hline
\end{tabular}

\section{Thermodynamics}

The thermodynamic analysis study for $20^{\circ} \mathrm{C}$ to $60^{\circ} \mathrm{C}$ are represented in figure 8. Gibbs free energy can be evaluated using equation (13).

$$
\Delta \mathrm{G}^{0}=-\mathrm{RT} \ln \mathrm{K}_{\mathrm{d}} \quad \text { Eqn..(13) }
$$

Where $K_{d}$, the distribution coefficient can be evaluated as $K_{d}=q_{e} / C_{e}$. Negative $\Delta \mathrm{G}^{0}$ values from table 6 , indicate a spontaneous physisorption as the values are less than $0 \mathrm{KJ} / \mathrm{mol}[4,68]$. Negative $\Delta \mathrm{H}^{0}$ values infer the exothermic nature of the $\mathrm{MB}$ dye removal process. $\Delta \mathrm{S}^{0}$ values are low indicating the randomness to be minimum among the adsorbent - dye solution interface [69].

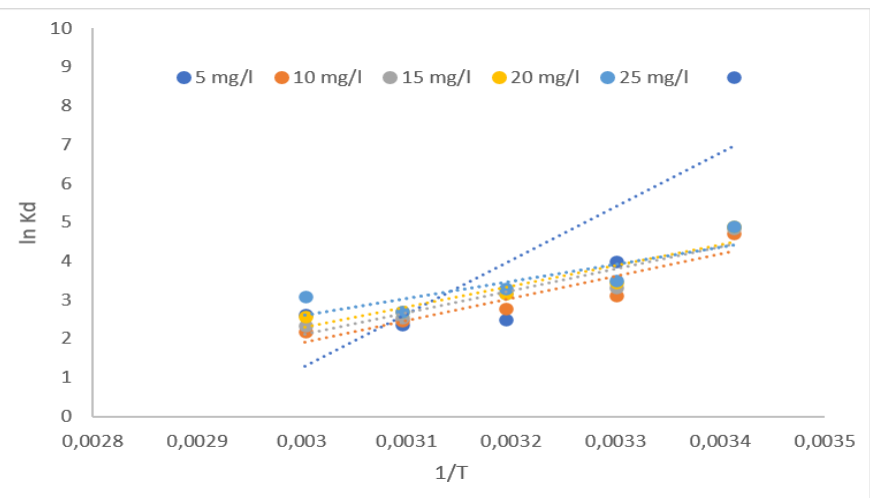

Figure 8. Van’t Hoff Graphene - MB adsorption plot.

Table 6. Thermodynamic parameters for graphene - MB dye adsorption

\begin{tabular}{|c|c|c|c|c|c|c|c|}
\hline \multirow{2}{*}{$\mathrm{C}_{0}(\mathrm{mg} / \mathrm{l})$} & \multirow{2}{*}{$\Delta \mathbf{H}^{0}(\mathbf{k J} / \mathbf{m o l})$} & \multirow{2}{*}{$\Delta \mathbf{S}^{0}$ (kJ.mol.K) } & \multicolumn{5}{|c|}{$\Delta G^{0}(J / m o l)$} \\
\hline & & & $20^{\circ} \mathrm{C}$ & $30^{0} \mathrm{C}$ & $40^{\circ} \mathrm{C}$ & $50^{0} \mathrm{C}$ & $60^{\circ} \mathrm{C}$ \\
\hline 5 & -193.39 & -1.5641 & -14253.78 & -8823.26 & -7562.36 & -6489.50 & -6501.75 \\
\hline 10 & -74.219 & 0.9051 & -6489.50 & -7934.29 & -7027.45 & -6284.56 & -5525.59 \\
\hline 15 & -72.639 & 1.139 & -8823.26 & -8432.92 & -8042.06 & -6446.60 & -5957.28 \\
\hline 20 & -69.3 & 1.3512 & -6501.75 & -8754.32 & -8051.03 & -6848.64 & -6529.50 \\
\hline 25 & -59.751 & 1.7651 & -7562.36 & -8874.33 & -8369.89 & -6884.31 & -7807.43 \\
\hline
\end{tabular}

\section{CONCLUSION}

Graphene of nano size is exfoliated electrochemically and characterized for further experimentation. This research work focusses on the adsorption between the as-prepared graphene nanoparticle and MB dye solution. Graphene powder with BET surface area of $710.4 \mathrm{~m}^{2} / \mathrm{g}$ shows high sorption capacity.

The initial external diffusion stage where the MB dye molecules attach to the adsorbent graphene surface was very fast. Adsorption isotherms were evaluated for the best fit wherein Freundlich isotherm best fits and Temkin adsorption isotherms describes the adsorption equilibrium well with a binding energy $\left(\mathrm{A}_{\mathrm{T}}\right)$ of $224 \mathrm{~L} / \mathrm{g}$. Maximum adsorption capacity of $272 \mathrm{mg} / \mathrm{g}$ has been reported by Langmuir isotherm model at $30^{\circ} \mathrm{C}$. Among the kinetic models, pseudo-secondorder kinetics with $231.12 \mathrm{mg} / \mathrm{g}\left(\mathrm{q}_{\max }\right)$ fitted best the MB-Graphene adsorption process. $\Delta \mathrm{G}^{0}$ values indicated a spontaneous physisorption and $\Delta \mathrm{H}^{0}$ values report the exothermic nature of the process. Hence the synthesized graphene can effectively adsorb MB dye from wastewater.

\section{CONFLICTS OF INTEREST/COMPETING INTERESTS}

On behalf of all authors, the corresponding author states that there is no conflict of interest.
FUNDING

Not applicable

\section{ACKNOWLEDGEMENT}

We acknowledge the HRTEM FACILITY at SRMIST set up with support from MNRE (Project No. 31/03/2014-15/PVSE-R\&D), Government of India. We acknowledge SRM institute of Science and Technology for providing "micro- Raman FACILITY". We acknowledge the XRD FACILITY at SRMIST set up with support from MNRE (Project No. 31/03/2014-15/PVSE- R\&D), Government of India. We acknowledge Nanotechnology Research Centre (NRC), SRMIST for providing the research facilities.

\section{AUTHORS' CONTRIBUTIONS}

K.Bogeshwaran: Conceptualization, Methodology, Investigation, Data curation, Writing - Original Draft preparation; K.Sathish Kumar: Project administration, Validation, Funding acquisition, Supervision; B.Karunanithi: Resources, Writing - Review \& Editing; M.Srividhya : Visualization ; G.Gowri: Investigation. 


\section{REFERENCES}

1. H. Ma, Y. Zhang, Q.H. Hu, D. Yan, Z. Yu, Z. Maolin, J. Mater. Chem. Eng. 22, 5914, (2012).

2. K.S. Novoselov, A.K. Geim, S.V. Morozov, D. Jiang, Y. Zhang, S.V. Dubonos, I.V. Grigorieva, A.A. Firsov, Sci. 306, 666, (2004).

3. V. Pandiyarasan, Archana J, Pavithra A, Ashwin W, Navaneethan M, Hayakawa Y, Ikeda H, Mater. Lett. 183, 123, (2017).

4. S. Thangavel, N. Raghavan, K. Krishnamoorthy, G. Venugopal, J. Alloys Compd. 665, 107, (2016).

5. K. Krishnamoorthy, A. Ramadoss, S.J. Kim, Sci. Adv. Mater. 5, 406, (2013).

6. K. Krishnamoorthy, M. Veerapandian, K. Yun, S.J. Kim, Carbon. 53, 38, (2012).

7. K. Krishnamoorthy, K. Jeyasubramanian, M. Premanathan, G. Subbiah, S.H. Shin, S.J. Kim, Carbon. 72, 328, (2014).

8. A.P. Kauling, A.T. Seefeldt, D.P. Pisoni, R.C. Pradeep, R. Bentini, R.V.B. Oliveira, K.S. Novoselov, A.H.C. Neto, Adv. Mater. 30, 1803784, (2018).

9. R. Ruoff, Nat. Nanotech. 3, 10, (2008).

10. J. Chen, B. Yao, C. Li, G. Shi, Carbon. (2013).

11. G. Udhayasankar, C. Ganesamoorthy, G. Rajkumar, Energy Sources, Part A. 40, 1209, (2018).

12. H.V. Tran, L.T. Hoang, C.D. Huynh, Chem. Phys. 535, 110793 (2020)

13. A.P. Meshram, M.K.P. Kumar, C. Srivastava, Diamond Relat. Mater. 105, 107795 (2020).

14. V.K. Garg, M. Amita, R. Kumar, R. Gupta, Dyes Pigm. 63, 243, (2004).

15. A. Dabrowski, Adv. Colloid Interface Sci.. 93, 135, (2001).

16. Y. Xie, B. Yan, H. Xu, J. Chen, Q. Liu, Y. Deng, H. Zeng, ACS Appl. Mater. Interfaces. 6, 8845, (2014).

17.H. Zollinger Color chemistry synthesis properties and applications of organic dyes and pigments, Wiley-Vch, Weinheim, (1987).

18. Y. Li, Q. Du, T. Liu, J. Sun, Y. Wang, S. Wu, Z. Wang, Y. Xia, L. Xia, Carbohydr. Polym. 42, 819, (2013).

19. S.T. Yang, S. Chen, Y. Chang, Y.A. Cao, Y. Liu, H. Wang, J. Colloid Interface Sci.. 359, 24, (2011).

20. S.A. Sanchez, G.F. Suarez, A.A. Martinez, J.M.D. Tascon, J. Colloid Interface Sci. 450, 91, (2015).

21. A. Chojnacki, K. Chojnacka, J. Hoffmann, H. Gorecki, Miner. Eng. 17, 933, (2004).

22. W.U. Senevirathna, H. Zhang, B. Gu, Water, Air, Soil Pollut. 215, 573, (2011).

23. V.K. Gupta, P.J. Carrott, M.M.L. Ribeiro Carrott, R.C. Suhas, Environ. Sci. Technol. 39, 783, (2009).

50. D. Kong, Z.X.Y. Gao, X. Zhang, R. Guo, X. Huang, X. Li, L. Zhi, Mater. Sci. Eng., R. 137, 1, (2019).

51. A.K. Mishra, S. Ramaprabhu, Desalination. 282, 39, (2011).

52. K. Zhang, K.C. Kemp, V. Chandra, Mater. Lett.. 81, 127, (2012).

53. G.Z. Kyzas, E.A. Deliyanni, K.A. Matis, J. Chem. Technol. Biotechnol. 89, 196, (2013).

54. Y. Qin, J. Li, X. Jin, S. Jiao, Y. Chen, W. Cai, R. Cao, Ceram. Int.. 46, 15379, (2020).

55. F. Kordi, A.K. Zak, M. Darroudi, M.H. Saedabadi, Chem. Pap.. 73, 1945, (2019).

56.Z.H. Huang, X.Y. Zheng, W. Lv, M. Wang, Q.H. Yang, F.Y. Kang, Langmuir. 27, 7558, (2011).

57. S.H. Lin, R.C. Lin, Environ. Technol. 20, 11, (1999).

58. T.S. Khayyun, A.H. Mseer, Appl. Water Sci. 9, 170, (2019).

59. N. Ayawei, S.S. Angaye, D. Wankasi, E.D. Dikio, Open J. Phys. Chem. 5, $56,(2015)$.

60. F. Marrakchi, M. Bouaziz, B.H. Hameed, Colloids Surf., A. 535, 157, (2017).
24. Y. Zhang, Y.F. Li, L.Q. Yang, X.J. Ma, L.Y. Wang, Z.F. Ye, J. Hazard. Mater. 178, 1046, (2010).

25. A. Gignone, M.D. Piane, M. Corno, P. Ugliengo, B. Onida, J. Phys. Chem. C. 119, 13068, (2015).

26. K.B. Tan, M. Vakili, B.A. Horri, P.E. Poh, A.Z. Abdullah, B. Salamatinia, Sep. Purif. Technol. 150, 229, (2015).

27. G. Fadillah, T.A. Saleh, S. Wahyuningsih, E.N.K. Putri, S. Febrianastuti, Chem. Eng. J. 378, 122140, (2019).

28. C. Hou, Q. Zhang, Y. Li, H. Wang, J. Hazard. Mater. 205, 229, (2012)

29. C. Wang, J. Zhou, J. Ni, Y. Cheng, H. Li, Chem. Eng. J. 253, 130, (2014).

30. L. Ai, J. Jiang, Chem. Eng. J. 192, 156, (2012).

31. X.L. Wu, Y. Shi, S. Zhong, H. Lin, J.R. Chen, Appl. Surf. Sci. 378, 80, (2016).

32. X. Wu, W. Jia, Chem. Eng. J. 245, 210, (2014).

33. F. Mashkoor, A. Nasar, J. Magn. Magn. Mater. 500, 166408, (2020)

34. J. Bu, L. Yuan, N. Zhang, D. Liu, Y. Meng, X. Peng, Diamond Relat. Mater. 101, 107604, (2020).

35. S.T. Yang, S. Chen, Y. Chang, A. Cao, Y. Liu, H. Wang, J. Colloid Interface Sci. 359, 24, (2011).

36. [G. Xie, P. Xi, H. Liu, F. Chen, L. Huang, Y. Shi, F. Hou, Z. Zeng, C. Shao, J. Wang, J. Mater. Chem. 22, 1033, (2012).

37. D. Ringot, B. Lerzy, K. Chaplain, J.P. Bonhoure, E. Auclair, Y. Larondelle, Bioresour. Technol. 98, 1812, (2007).

38. G. Wang, B. Wang, J. Park, Y. Wang, B. Sun, J. Ya, Carbon. 47, 3242, (2009).

39. A.M. Abdelkader, I.A. Kinloch, R.A.W. Dryfe, ACS Appl. Mater. Interfaces. 6, 1632, (2014)

40. F.T. Johra, J.W. Lee, W.G. Jung, J. Ind. Eng. Chem. 20, 2883, (2014)

41. S. Kang, T. Yu, T. Liu, S. Guan, J. Colloid Interface Sci. 512, 489, (2018).

42. I. Abidat, C. Morais, S. Pronier, N. Guignard, J.D. Comparot, C. Canaff, T.W. Napporn, A. Habrioux, S. Mamede, J.F. Lamonier, K.B. Kokoh, Carbon. 111, 849, (2017).

43. A.C. Ferrari, Solid State Commun. 143, 47, (2007).

44. V.P. Parvathi, M. Umadevi, R.B. Raj, J. Environ. Manage. 162, 299, (2015).

45. Z. Wu, H. Zhong, X. Yuan, H. Wang, L. Wang, X. Chen, G. Zeng, Y. Wu, Water res. 67, 330, (2014).

46. T. Wu, X. Cai, S. Tan, H. Lia, J. Liu, W. Yang, Chem. Eng. J. 173, 144, (2011).

47. M. Baumgartner, R.J. Bakker, Mineral. Petrol. 95, 1, (2009)

48. L.G. Cancado, K. Takai, T. Enoki, M. Endo, Y.A. Kim, H. Mizusaki, A. Jorio, L.N. Coelho, R.M. Paniago, M.A. Pimenta, Appl. Phys. Let. 88, 163106, (2006).

49. S. Uran, A. Alhani, C. Silva, AIP Adv. 7, 035323, (2017).

61. L. Hu, Z. Yang, L. Cui, Y. Li, H.H. Ngo, Y. Wang, Q. Wei, H. Ma, L. Yan, B. Du, Chem. Eng. J. 287, 545, (2016).

62. C. Yu, G. Li, L. Wei, Q. Fan, Q. Shu, J.C. Yu, Catal. Today. 224, 154, (2014).

63. X. Wang, L. Dou, L. Yang, J. Yu, B. Ding, J. Hazard. Mater. 324, 203, (2017).

64. Y.Q. Li, J.Y. Qu, F. Gao, S.Y. Lv, L. Shi, C.X. He, J.C. Sun, Appl. Catal., B. 162, 268, (2015).

65. M. Fan, J. Zhang, F. Yuan, W. Zhang, X. Chen, C. Chen, Y. Huang, J. Qian, D. Sun, Chem. - Eur. J. 24, 14554, (2018).

66. S. Choudhury, R. Balasubramanian, Adv. Colloid Interface Sci.. 204, 35 , (2014).

67. Y. Ling, Q. Gao, C.F. Ma, Y.S. Gong, H. Bo, K.S. Xia, C.G. Zhou, RSC Adv. 6, 23360, (2016).

68. T.A. Saleh, S.H.A. Ruwayshid, A. Sari, M. Tuzen, Eur. Polym. J. 130, 109698, (2020).

69. E.A. Abdelrahman, R.M. Hegazey, R.E.E. Azabawy, J. Mater. Res. Technol. 8, 5301, (2019). 